\title{
Application of ARCS Motivation Model in CET-SET Examination
}

\author{
Rongjian Zeng* \\ Guangzhou Songtian Vocational College, Guangzhou 511300, China \\ *Corresponding author: Rongjian Zeng, wooljian3184@sina.com
}

\begin{abstract}
Based on Guangzhou Songtian Vocational College under the China Education Group, with the guidance of ARCS (attention, relevance, confidence, and satisfaction) motivational model, the scientific examination should not only be before the examination but also after the examination which can produce positive and negative factors for examinees. Through the data collected in the recent three years, it can be drawn that the CET-SET (College English Test-Spoken English Test) has a backwash effect on the examinees especially on the learning concepts, learning motivations, as well as guiding students to develop good oral learning strategies and habits.
\end{abstract}

Keywords: ARCS motivation model; CET-SET; Oral test

Publication date: July 2021; Online publication: July 30, 2021

\section{Introduction}

After the outbreak, the evaluation of teaching quality in higher vocational colleges is mainly to improve students' learning experience at home. Through a careful study, in view of the teaching group, two keywords are pointed out which are ARCS model and backwash effect. In order to find out whether the CET-SET under the ARCS model continues to produce backwash effect on the examinees after the test, this study adopted a combination of qualitative and quantitative analysis methods to conduct the research. This study randomly selected students from different majors of Guangzhou Songtian Vocational College in Xiazengcheng District under the China Education Group and conducted a survey as well as interviews. The quantitative data obtained were mainly analyzed by statistical methods whereas the qualitative data were analyzed by classification.

\section{Research methods}

\subsection{Theoretical framework}

The main theories of this study include:

(1) ARCS motivation model is a heuristic model. It enables teachers to understand the factors that affect students' motivation, analyze the situation of their motivation, as well as determine the focus and strategy of motivation so as to raise the possibility of teaching success. Tests are ways to measure a person's knowledge and ability in a particular range. This definition points out that testing must have four aspects which include testing is a method, testing is for the purpose of evaluating, the subject of testing is knowledge and ability, and testing is limited to a specific scope. The main purpose of language testing is to justly and accurately measure as well as evaluate the language ability of the subjects. With the expanding theoretical research on language testing, it is generally believed that language testing has a comprehensive, profound, and positive influence on language 
teaching. The term used to explain this influence is backwash. At present, there are many kinds of translation methods such as reaction effect, backwash effect, and backsplash effect. This article used the formulation of the backwash effect. The term "backwash effect" refers exclusively to the influence or reaction of testing on teaching (including teaching and learning) in the field of education. Foreign linguists have several explanations where the backwash effect for teachers and students have a natural drive, that is to make the teachers teach and students study according to the test requirements especially when the test is extremely important for future purposes. When the pass rate of a test forms the basis of teachers' teaching evaluation, of course the effect of the test on teaching and learning (specifically to language testing) is important. This kind of backwash effect has positive as well as negative influences.

(2) Alderson and Wall with their 15 hypotheses on backwash effect, Bailey Hughes based on the PPP (participants, processes, products) theory put forward the backwash effect factor model, as well as the overt and covert backwash effect of Rodomont. Alderson and Wall's 15 hypotheses on backwash effect outlined that tests are for teachers' teaching contents, teaching methods, students' learning content, learning method, the speed and order of teaching and learning, teaching and learning, as well as the extent and depth of teaching and learning attitude. Bailey's PPP model of backwash effect emphasized that a test would have an impact on the participants during each process, thus producing corresponding effects including pre-backwash as well as post-backwash factors. Rodomont divided the backwash effect into two forms which are the overt and the covert backwash effect. The overt backwash effect refers to direct and obvious exam-oriented teaching or learning while the covert backwash effect is a deep and imperceptible influence on teaching.

\subsection{Subject}

The subjects of this study included students from the oral English course and finance class of Guangzhou Songtian Vocational College in 2019. They had passed the College English Test in June 2018 and were eligible for the Spoken English Test. Sixty-two from 102 students in the class were randomly selected as the subjects. The subjects participated in two survey questionnaires which were held before and after the oral examination, respectively and then, 12 students ( 8 boys and 4 girls) were randomly selected to participate in an interview.

\subsection{Measuring tools}

The main measurement tools for this study were questionnaires and individual interviews. Two questionnaires were conducted in which the first was before the CET-SET and the other was after the test with the purpose of comparing the backwash effect before and after the CET-SET. According to the United States backwash, a questionnaire was designed for 63 backwash effect factor hypotheses. In order to facilitate the research, the contents of the two questionnaires were similar which included effective ways of learning English, focus of learning English, obstacles in improving English proficiency, effective methods to pass the oral English test, necessity of oral English test, etc. The interviews were conducted to further investigate the results of the two questionnaires and to explore the reasons. They were conducted in a one-to-one and face-to-face setting between the surveyor and the selected students in which the interviews were recorded one by one. 


\subsection{Research procedure}

The CET-SET in 2019 was held on November 23 to 24 of that year. The questionnaires were given to the subjects in March 2019 and June 2020, respectively followed by the interviews.

\section{Data analysis}

\subsection{Contents of the questionnaire}

The contents of the questionnaires were as follows:

Question 1: In your opinion, the most effective way to learn English is (1) Going for English classes; (2) Prepare and review texts; (3) Learn grammar and words; (4) Memorize fixed patterns; (5) Read articles; (6) Recite model essay reading exercises; (7) Carry out English extracurricular readings from newspapers, magazines, novel, etc.; (a) Carry out listening exercises; (b) Listen to English original materials such as from the radio, television, movies, English songs, etc.; (c) Speaking with foreigners in English; (d) Speaking with teachers, classmates, and friends in English; (e) Do mock exams; (f) Take part in English tutoring classes; (g) Use multimedia English learning software.

Question 2: In your opinion, the focus of learning English is (1) To improve listening ability; (2) To improve speaking ability; (3) To improve reading ability; (4) To improve writing ability; (5) To learn grammar knowledge; (6) To improve the comprehensive ability of English language.

Question 3: The obstacle for you to improve your level of spoken English is (1) Inadequate knowledge of English in terms of grammar, vocabulary, pronunciation, etc.; (2) Do not know the way to learn spoken English; (3) Worried about being a joke, hence afraid to speak; (4) It is difficult to find a partner to practice with; (5) Do not have time to practice speaking; (6) Lack of motivation to improve; (7) Lack of resources such as books, audios, videos, equipment, etc.

Question 4: What do you think is an effective method to pass CET-SET? (1) Review the text preview, memory word grammar, learning all kinds of fixed memory patterns; (2) Read articles; (3) Recite model essays; (4) Strengthen English reading skills; (5) Strengthen English listening skills; (6) Practice English writing; (7) Practice English conversations; (8) Utilizing the universities' CET-SET example questions; (9) Take part in CET-SET university classes; (10) Use multimedia English learning software; (11) Ask a tutor for help; (12) Learn the exam outlines; (13) Refer to sample questions on compact discs; (14) Get to know the CET-SET of the university through various channels such as consulting the teacher or previous candidates; (15) Predict the questions or the topic range for the coming examination.

Question 5: Does CET-SET reflect your speaking ability?

Question 6: What do you think is the importance of CET-SET in universities? (1) To understand spoken English; (2) Able to strengthen self-confidence in English after having obtained the certificate; (3) Have the advantage to find a job after graduation; (4) To prepare for other oral test; (5) For teachers to understand students' spoken English levels; (6) To urge students to learn to speak English.

Question 7: Do you think it is unnecessary to take CET-SET? The reason why I do not think it is necessary to take CET-SET is (1) The test is not well-designed and does not reflect my speaking ability; (2) Students are not required to pass CET-SET; (3) Most students fail to pass the test; (4) Students' written test scores generally fail to meet the requirements; (5) Taking the exam will increase my burdens in studies.

\subsection{Record of the questionnaire data}

Firstly, the answers of the two questionnaires were converted digitally. The method of numerical conversion was as follows: Each of the six major questions in the two questionnaires were given three or four choices. 
For example, the first question was regarding what the students thought was the most effective way to learn English. The choices of "Very important," "Important," "Not important," and "Not important at all" under "Going for English classes" were 5, 3, 1, and 0 point, respectively and so on. After the digital conversion, the score of each question was arranged into a table to produce the "General Table of Questionnaire Survey Data." The answers to the open questions were sorted into a data summary table.

\subsection{Statistical tools}

For the analysis of quantitative data, Excel spreadsheet and Statistical Package for the Social Sciences (SPSS) software were used.

\section{Result and discussion}

The purpose of this study was to compare and analyze the data of two questionnaires to explore whether the backwash effect factors continue to occur after CET-SET. Here are six ways to look at the problem based on the data collected.

\subsection{Effective English learning methods}

In terms of learning methods, compared with before the exam, in addition to "listening exercises" and "doing simulated test questions," after the exam, all the other learning methods were of varying degrees whereas "recite model essays," "read articles," and "use multimedia learning software" increased. Compared with others, these were the most prominent features of students' learning methods. This showed that the college CET-SET has some positive and some negative factors in students' language learning. The students created an environment for language learning by reciting and reading aloud. The diversity of learning methods and the choice of language materials all reflected that the students paid more attention to the training of their oral skills. At the same time, the interview data also reflected that after preparing for the CET-SET, their motivation to speak English was enhanced and it also strengthened their habit of thinking in English.

\subsection{Focus of learning English}

According to the survey, there were small changes in the focus of students' English learning before and after CET-SET. Compared with the period before the test, only "to improve listening ability" fell by $3.2 \%$ meaning that students focused more on listening practice before the test. According to the information obtained from the interview, students paid attention to the training of listening skills before the exam mainly because they were worried about not understanding the examiner's questions. In the actual speaking test, the main problem was not understanding but the expression of some issues. Therefore, after the exam, most students felt that improving oral skills and having a comprehensive English ability were the focus of English learning. It can be seen that the focus of students' English learning after the test was inclined to their oral skills and comprehensive English ability which is also the purpose of implementing CET-SET test in universities. Therefore, it can be said that in adjusting the focus of learners' English learning, this test has produced some positive and negative factors.

\subsection{Obstacles in improving oral English}

Before and after the CET-SET, students generally had the same understanding of the obstacles in improving their oral English level especially factors such as "inadequate English knowledge," "difficulty in finding a 
partner to practice with," and "lack of motivation to improve." This was confirmed in the interviews where students felt that the above-mentioned were the main factors affecting the improvement of their oral English level.

\subsection{Effective methods for passing CET-SET}

According to the survey, before and after the CET-SET, there were significant cognitive differences among students in regard to the effective methods of passing the CET-SET. Before the test, the backwash effect of oral English test was mainly reflected in the test itself where the students felt that the most effective ways to pass the exam were to guess the scope of the questions, learn about CET-SET through various sources, and to review previous CET-SET questions. After the exam, students paid more attention to good language learning strategies such as preview, text review, memorizing various fixed sentence patterns, reciting articles, strengthening English reading, using multimedia English learning software, practice English writing, as well as practice English conversations. After the test, the students' views on the effective methods to pass CET-SET changed which showed that CET-SET had a backwash effect on the students. After the exam, they paid more attention to the language itself and were inclined to adopt better language learning strategies.

\subsection{Importance of university CET-SET examination}

The fifth question; "Does CET-SET reflects your speaking ability?" was answered positively after the test by an average of $4.7 \%$ more students than before the speaking test. According to the interview data, all the students consistently reported that they had not expected the exam pressure of the oral exam because this kind of examination format was rarely experienced in their previous exams. In addition, some students also felt that their language proficiency may be affected by the language proficiency of their peers, the familiarity of the contents in the test, as well as their adaptability to change on the spot. That makes sense. Why do students think that the test does not reflect their language level correctly to some extent?

In the questionnaire, only the average values of "for teachers to understand students' spoken English levels" and "to urge students to learn to speak English" had improved. That is to say, CET-SET does not only make students and teachers understand the students' oral English levels but it also promotes a positive backwash effect in oral English learning.

Instead, through the university CET-SET, it could be seen that the students that felt the need to take the exam decreased by $2.1 \%$ on average and all the reasons listed in the survey before the exam decreased. "Most of the students fail to pass the test," "students are not required to pass CET-SET by the university," and "students' written test scores generally fail to meet the requirements" fell by $80 \%, 69 \%$, and $50 \%$, respectively.

\subsection{Comparative analysis}

The overall quantitative questions in the questionnaire data analysis according to Table 1 shows that questionnaire 1 and questionnaire 2 were at an average difference of $2.37 \%$ and were not significantly different, close to the average of 18 major problems, even if there were some differences. Once again, it shows that there were minor differences in the students' learning methods, focus of English learning, and effective methods of passing the test before and after CET-SET. That is to say, CET-SET continues to exert a backwash effect on students' language learning not only before but also after the test. 
Table 1. Comparative analysis of the quantitative data of questions 1 to 7

\begin{tabular}{lccccccc}
\hline Project & Topic quiz & 1 & 2 & 3 & 4 & 5 & 6 \\
\hline Average & Topic quiz & 2.29 & 3.18 & 2.46 & 2.32 & 2.18 & 2.19 \\
& Topic quiz & 2.84 & 1.90 & 2.34 & 2.67 & 2.19 & 2.36 \\
& Topic quiz & 3.67 & 2.85 & 2.34 & 2.46 & 2.17 & 3.85 \\
& & & & & & & \\
& Topic quiz & 3.34 & 2.67 & 2.85 & 2.76 & 2.34 & 3.34 \\
\hline Pariance values & & 6.05 & 6.05 & 6.05 & 6.05 & 6.05 & 6.05 \\
T value & & 346.07 & 346.07 & 366.07 & 656.07 & 4376.07 & 356.07 \\
Sig. & & 6.000 & 4.000 & 5.000 & 5.000 & 5.000 & 6.000 \\
\hline
\end{tabular}

\section{Conclusion}

Backwash effect factor is an important criterion to measure large-scale effect. A scientific examination that is carried out not only before the examination but also after the examination can produce positive and negative effect factors to its examinees. Through the comparative analysis of the collected data, this study preliminary draws the following conclusion: CET-SET continues to have a backwash effect on examinees after the end of the test especially in terms of learning concepts, learning motivations, and guiding students to develop good oral learning strategies and habits. Therefore, according to the data of this study, it can be concluded that CET-SET is a relatively scientific test.

\section{Disclosure statement}

The author declares that there is no conflict of interest.

\section{References}

[1] Zhang J, 1993, Language Education, Zhejiang Education Press, Hangzhou, 129.

[2] Wang Q, 2006, Teaching Methods in English (Second Edition), Higher Education Press, Beijing.

[3] Juan DA, 2007, Cultivating Students' Cultural Awareness by Integrating Cultural Teaching and Interaction in Middle School English. Liaoning Normal University.

[4] Newmark P, 2004, A Textbook of Translation, Shanghai Foreign language Education Press.

[5] Xie S, Flower, MG, 2016, Classroom Design of English Teaching in Higher Vocational Colleges from the Perspective of Information-based Teaching. Journal of Guangxi Vocational and Technical College, (3): 44-6.

[6] Huang J, 2016, Research on the Teaching Design of Flipped Classroom in Higher Vocational Colleges under the Information Environment. Guangxi Education, (3): 114-5.

[7] Wang W, 2017, Research on the Teaching Design of Higher Vocational College English under the Information Environment. Journal of MadEnglish (Theoretical Edition), (03): 67-9. 